\title{
Electron Microscopic Comparative Analysis of Smear Layer Removal by Ethylenediaminetetraacetic Acid and Chitosan Using Ultrasonic Activation: An In Vitro Study
}

\author{
Chakravarthy S Vineetha ${ }^{1}$, Ravi Vaiyapuri ${ }^{2}$, Arthanarieswaran A Sivakumar ${ }^{3}$, Jambai S Sivakumar ${ }^{4}$, Anjaneya S Prasad $^{5}$, \\ Saravanapriyan Soundappan ${ }^{6}$
}

\begin{abstract}
Aim: To compare the ability of smear layer removal by ultrasonic activation of ethylenediaminetetraacetic acid (EDTA) and chitosan.

Materials and methods: Forty-five freshly extracted human mandibular single-rooted premolars were collected and stored in distilled water. Teeth were radiographed to confirm the existence of a single canal. The crowns were sectioned to standardize the length of the root samples to $14 \mathrm{~mm}$ using a diamond disk under constant irrigation. Cleaning and shaping were done up to ProTaper F3, and the specimens were randomly divided into three groups of 15 samples each - group I-control group (ultrasonically activated-normal saline), groups II (ultrasonically activatedEDTA), and group III (ultrasonically activated-chitosan). After this, the roots of the teeth were split longitudinally, and the samples were placed in $2 \%$ glutaraldehyde for 24 hours. The samples were then desiccated, mounted, and scanning electron microscopic (SEM) photographs were taken at coronal, middle, and apical levels. Data were collected based on Gutmann's scoring criteria, and statistical analysis was carried out using one-way ANOVA and Tukey's post hoc test $(p<0.05)$.

Results: Ultrasonic activation of EDTA had the highest ability of smear layer removal.

Conclusion: Ultrasonically activated EDTA and chitosan showed significant difference in smear layer removal compared to normal saline; EDTA was found to be better than chitosan.

Keywords: Chitosan, Ethylenediaminetetraacetic acid, Scanning electron microscopy, Smear layer, Ultrasonics.

Journal of Operative Dentistry and Endodontics (2019): 10.5005/jp-journals-10047-0073
\end{abstract}

\section{INTRODUCTION}

The success of an endodontic procedure majorly lies on three important factors-creating straight-line access, proper cleaning and shaping of the canals, and producing three-dimensional obturation with a good seal. Instrumentation during cleaning and shaping of root canal leads to the formation of smear layer. Smear layer contains inorganic debris and organic material. The organic material includes vital and necrotic pulpal tissues, microorganisms and their metabolic products, and odontoblastic processes..$^{1-3}$ Literature currently available supports the removal of smear layer for improved disinfection and better adaptation of materials to the canal walls. ${ }^{4-7}$ The organic portion of the smear layer is routinely removed using sodium hypochlorite, whereas the gold standard for the removal of inorganic component is EDTA. ${ }^{8}$ Although EDTA is an effective chelating agent, the disadvantages of using it as an irrigating solution, include dentinal erosion, its harmful effect on periapical tissues, inactivation of sodium hypochlorite, and its lack of antimicrobial property. ${ }^{9}$ This has led researchers to seek more biocompatible material as an alternative. Chitosan, a recently developed biopolymer, is reported to be effective in the removal of smear layer. It has an additional antibacterial property and is highly biocompatible. ${ }^{10,11}$ Several studies have shown that ultrasonic activation improves the efficacy of the chelating agents in the removal of smear layer. The cavitational effect produced on the canal walls by ultrasonic agitation was found to have improved effects in combination with various irrigating solutions. ${ }^{12-16}$ Hence, this study was conducted to evaluate the ability of smear layer removal of ultrasonically activated chitosan as compared to ultrasonically activated EDTA.

\footnotetext{
${ }^{1-6}$ Department of Conservative Dentistry and Endodontics, Vivekanandha Dental College for Women, Tiruchengode, Tamil Nadu, India

Corresponding Author: Chakravarthy S Vineetha, Department of Conservative Dentistry and Endodontics, Vivekanandha Dental College for Women, Tiruchengode, Tamil Nadu, India, Phone: 04288 234891, e-mail: vinyme92@gmail.com
}

How to cite this article: Vineetha CS, Vaiyapuri R, et al. Electron Microscopic Comparative Analysis of Smear Layer Removal by Ethylenediaminetetraacetic Acid and Chitosan Using Ultrasonic Activation: An In Vitro Study. J Oper Dent Endod 2019;4(1):37-41.

Source of support: Nil

Conflict of interest: None

\section{Materials and Methods \\ $0.2 \%$ Chitosan Solution Preparation}

The electronic weighing device was used to measure $0.2 \mathrm{~g}$ of low molecular weight chitosan. The solution was prepared by dissolving $0.2 \mathrm{~g}^{17}$ of chitosan in $100 \mathrm{~mL}$ of $1 \%$ acetic acid. A heated magnetic stirrer was used to agitate this solution for 2 hours to obtain a homogenous clear solution. ${ }^{18}$

\section{Sample Preparation}

A total of 45 freshly extracted mandibular single-rooted premolars were taken for the study. Teeth extracted for periodontal or orthodontic reasons, which were non-carious with straight patent roots and fully formed apices were included in the study. Radiographs were taken in the buccolingual and mesiodistal direction of all the samples to confirm the selection criteria adopted 
for the study. Teeth were stored in $10 \%$ formalin solution until they were used for the study. The root surfaces were cleaned and then decoronated using a diamond disc under constant water irrigation to obtain a standard root length of $14 \mathrm{~mm}$. Instrumentation of root canal was initiated with ISO hand files up to \#20 followed by ProTaper rotary files up to size F3, employing the step-back technique. In between every change of instrument, the canal was irrigated with $2 \mathrm{~mL}$ of $3 \% \mathrm{NaOCl}$. The irrigants were delivered with a disposable syringe and a 30-gauge needle placed $1 \mathrm{~mm}$ short of the working length. Finally, $3 \mathrm{~mL}$ of $3 \% \mathrm{NaOCl}$ was used to flush out to the debris from the root canals followed by a final rinse with $3 \mathrm{~mL}$ of distilled water to terminate any action of the solvents remaining in the canal.

\section{Grouping of Samples}

After cleaning and shaping the samples were divided into three groups of 15 specimens each.

\section{Group I (Control) - Ultrasonically Activated Normal Saline}

Root canals were filled with $1 \mathrm{~mL}$ of normal saline and agitated with passive ultrasonic activation for 1 minute with a \#20/21 mm ultrasonic $U$-file placed $1 \mathrm{~mm}$ short of the working length, followed by $3 \mathrm{~mL}$ of $3 \% \mathrm{NaOCl}$.

\section{Group II-UItrasonically Activated EDTA}

The root canals were filled with $1 \mathrm{~mL}$ EDTA and agitated with passive ultrasonic activation for 1 minute with a \#20/21 mm ultrasonic $\mathrm{U}$-file placed $1 \mathrm{~mm}$ short of the working length, followed by $3 \mathrm{~mL}$ of $3 \% \mathrm{NaOCl}$.

\section{Group III-Ultrasonically Activated Chitosan}

The root canals were filled with $1 \mathrm{~mL} 0.2 \%$ Chitosan and agitated with passive ultrasonic activation for 1 minute with a \#20/21 mm ultrasonic $U$-file placed $1 \mathrm{~mm}$ short of the working length, followed by $3 \mathrm{~mL}$ of $3 \% \mathrm{NaOCl}$.

The root canals were finally flushed with $5 \mathrm{~mL}$ of distilled water to terminate the action of the irrigating solutions, dried and prepared for SEM examination.

\section{Scanning Electron Microscopic Analysis}

The teeth were grooved along the buccal and lingual planes by using a diamond disc at low speed. The roots were then split longitudinally with a bi-beveled chisel and a mallet. One-half of each root was selected depicting the entire root canal length and prepared for SEM examination. The selected samples were progressively dehydrated using graded concentrations of aqueous ethanol $(70 \%, 80 \%, 90 \%$, and $100 \%$ ) for 24 hours at each concentration. After dehydration, samples were placed in a vacuum chamber and sputter-coated with a $30 \mathrm{~nm}$ gold layer. The root canal wall was examined at coronal, middle, and apical thirds at a magnification of $\times 2,000$ and $\times 5,000$ for the presence or absence of smear layer and patency of dentinal tubules. Photographs of the root canals were taken at the coronal, middle, and apical level for scoring individually in a calibrated single-blind manner according to the rating system developed by Gutmann et al. ${ }^{19}$

\section{Scoring Criteria}

Gutmann rating system for remaining smear scores ${ }^{19}$

\begin{tabular}{ll}
\hline Score & Criteria \\
\hline 1 & Little or no smear layer; covering $25 \%$ of the specimen most \\
tubules were visible and patent or almost complete laser melting
\end{tabular}

Contd...

\begin{tabular}{ll}
\hline $\begin{array}{l}\text { Contd... } \\
\text { Score }\end{array}$ & Criteria \\
\hline 2 & $\begin{array}{l}\text { Little to moderate or patchy mounts of smear layer, cover- } \\
\text { ing } 25-50 \% \text { of the specimen; many tubules visible and } \\
\text { patent, or laser melting }\end{array}$ \\
\hline 3 & $\begin{array}{l}\text { Moderate amounts of scattered or aggregated smear layer; } \\
\text { covering } 50-75 \% \text { of the specimen; minimal to no tubule } \\
\text { visibility or patency, or scattered laser melting }\end{array}$ \\
4 & $\begin{array}{l}\text { Heavy smear layer covering }>75 \% \text { of the specimen; no tubule } \\
\text { orifices were visible or patent; or no visible laser melting }\end{array}$ \\
\hline
\end{tabular}

Data were analyzed using a one-way analysis of variance using SPSS version 20 (IBM Corp, Armonk, NY, USA) and Tukey's post hoc tests $(p<0.05)$

\section{Results}

There was a statistically significant difference in smear significant layer removal among the three groups. There was no difference in smear layer removal in the apical, middle, and coronal levels (Table 1). The surfaces of samples in the normal saline group were covered with a heavy layer of debris (Figs 1 and 2). EDTA had the highest ability of smear layer removal (Figs 3 and 4), followed by chitosan (Figs 5 and 6), which was better than saline. Saline had the lowest ability of smear layer removal (Table 2).

\section{Discussion}

The disinfection of dentin walls using irrigants is adversely affected in the presence of a smear layer by blocking them from entering dentinal tubules. ${ }^{20}$ It also adversely affects sealer penetration and increases microleakage following obturation leading to increased intra-canal microflora. ${ }^{21,22}$ Hence, to enhance sealer penetration and a fluid-tight seal, it is necessary to remove the smear layer. There has been an increasing interest in developing new irrigating solutions and systems due to the limitations of the currently available ones.

In the current study, ultrasonics was used as an adjunct to irrigation. This was because several studies showed that ultrasonic activation of irrigants increased the smear layer removal by enhancing the penetration of irrigating solution into the narrow apical regions of the root canals. ${ }^{13-16}$ The file oscillations are primarily responsible for the production of acoustic streaming (vortex-like motion). Acoustic streaming may also be associated with the occurrence of cavitation, which enhances smear layer removal. ${ }^{20,23}$ When endodontic files are used in the handpiece, the files oscillate along the longitudinal axis of the instrument, with maximal amplitude occurring at the antinodes and minimal oscillation at the nodes. ${ }^{24}$ According to Walmsley et al., the least smear layer removal was found in the apical third because the oscillation of the tips of the ultrasonic instrument is decreased by constraining it in the root canal. Because the amplitude of the oscillation is largest at the instrument's tip, any attenuation affects the apical part most significantly where the diameter of the canal is smallest. ${ }^{24}$

Table 1: Mean remaining smear layer scores among various groups

\begin{tabular}{llll}
\hline Area recorded & $\begin{array}{l}\text { Group I } \\
\text { (normal saline) }\end{array}$ & $\begin{array}{l}\text { Group II } \\
\text { (EDTA) }\end{array}$ & $\begin{array}{l}\text { Group III } \\
\text { (chitosan) }\end{array}$ \\
\hline Coronal third & 3.2 & 1.4 & 2.4 \\
Middle third & 3.3 & 1 & 2.4 \\
Apical third & 3.8 & 1 & 1.4 \\
Total & 10.3 & 3.4 & 6.2 \\
\hline
\end{tabular}




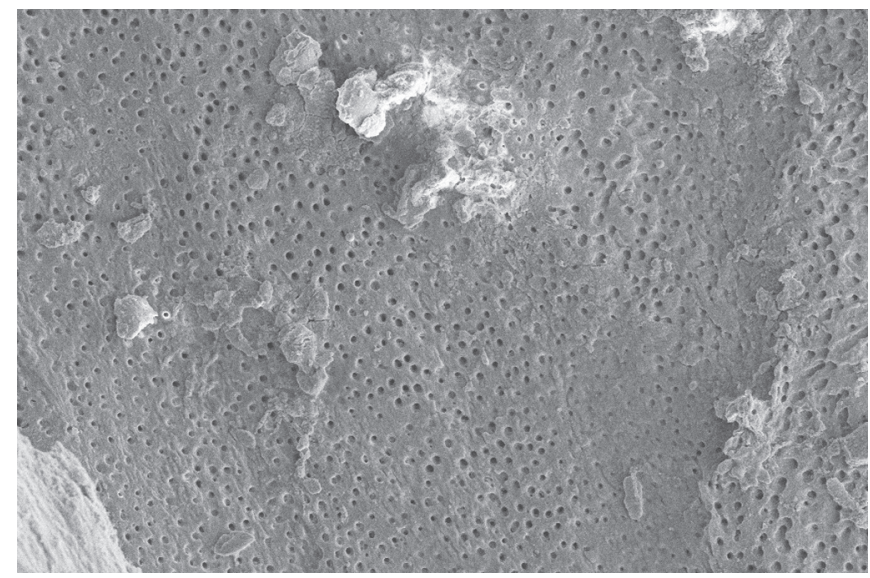

Fig. 1: 2000× magnification—Normal saline group

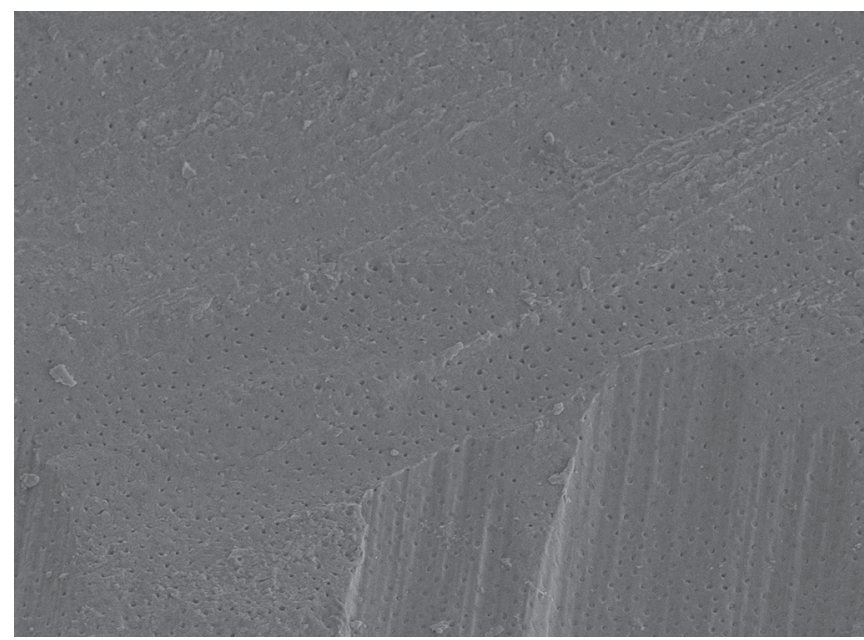

Fig. 3: 2000× magnification-EDTA group

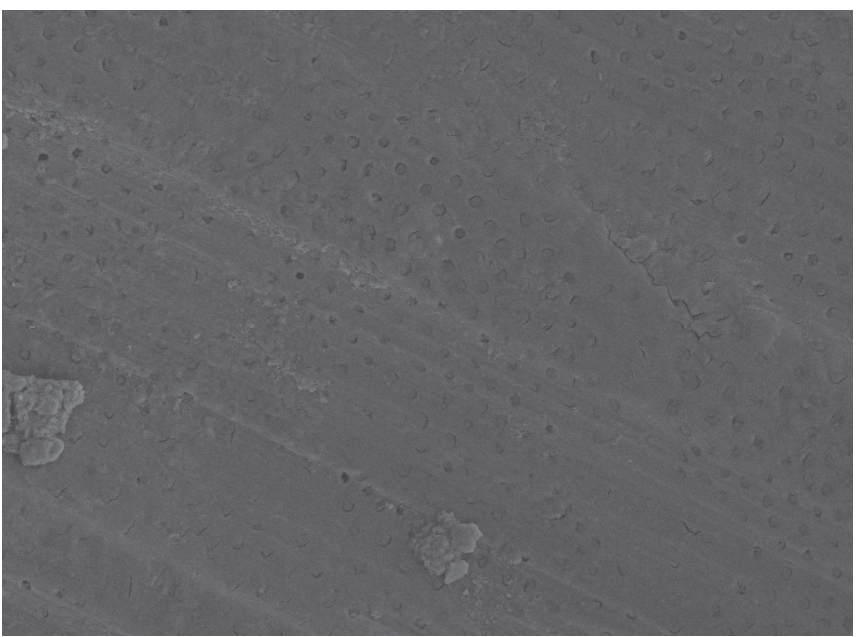

Fig. 5: 2000× magnification-Chitosan group

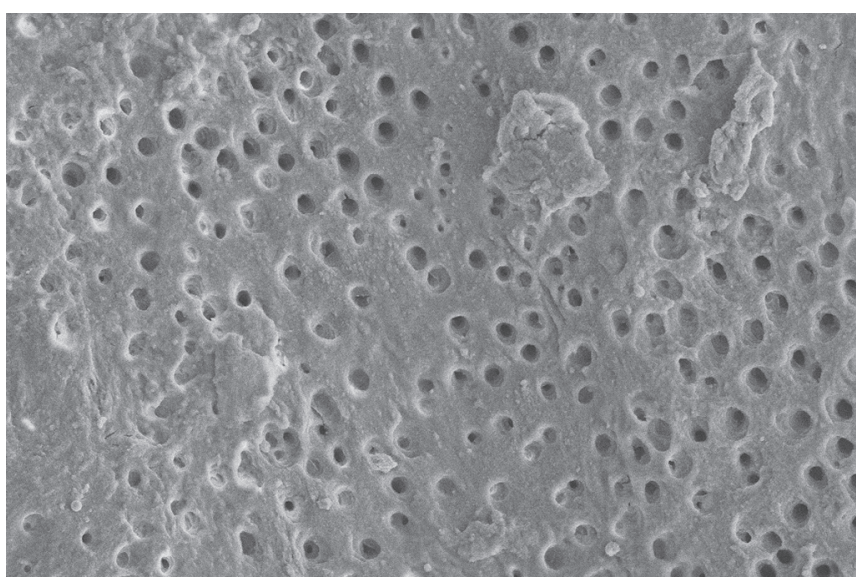

Fig. 2: 5000× magnification—Normal saline group

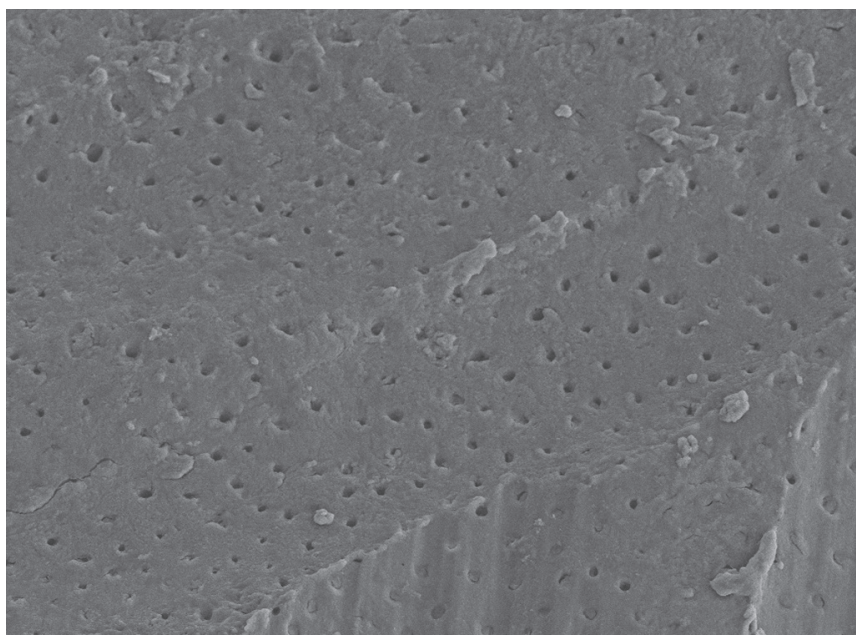

Fig. 4: 5000× magnification-EDTA group

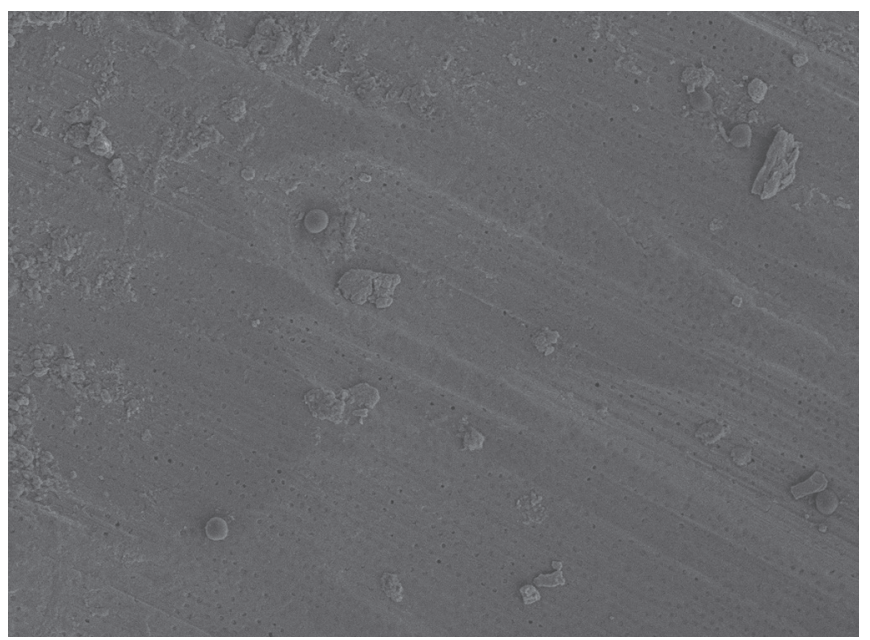

Fig. 6: 5000× magnification-Chitosan group

Table 2: Intergroup comparison of remaining smear layer scores at various levels

\begin{tabular}{lcccccc}
\hline Groups & Mean difference & $p$ value & Mean difference & $p$ value & Mean difference & $p$ value \\
\hline I vs II & 1.800 & 0.000 & 2.333 & 0.000 & 2.800 & 0.000 \\
I vs III & 0.800 & 0.000 & 0.9333 & 0.000 & 2.400 & 0.000 \\
II vs III & -1.000 & 0.000 & -1.4000 & 0.000 & -0.400 & 0.004 \\
& \multicolumn{2}{c}{ Coronal } & & Middle & Apical \\
\hline
\end{tabular}


This was not in accordance with the current study in which EDTA and chitosan showed effective smear layer removal from coronal, middle, and apical third with no statistical difference. This could be because the working width of the samples used in the current study was greater, thus providing adequate space for the oscillation of the tip of the ultrasonic instrument.

The effect of smear layer removal by chitosan was compared to that of EDTA because EDTA has been accepted as a gold standard for removal of smear layer. ${ }^{25}$ It promotes decalcification by chelating the calcium ions in dentine at approximate depths of 20-30 $\mu \mathrm{m}$ within 5 minute. ${ }^{26}$

Chitosan is a natural, cationic amino polysaccharide copolymer of glucosamine and $\mathrm{N}$-acetyl glucosamine obtained by the alkaline, partial deacetylation of chitin. It is obtained from shells of crustaceans and shrimps. ${ }^{27}$ It has biocompatibility, biodegradability, bioadhesion as well as antimicrobial activity. ${ }^{28}$ It can also chelate various metal ions such as $\mathrm{Fe}^{2+}, \mathrm{CO}^{2+}, \mathrm{Mg}^{2+}, \mathrm{Zn}^{2+}$, and $\mathrm{Cu}^{2+}$ respectively in acid conditions. As it is hydrophilic, it is adsorbed on the root canal wall. ${ }^{29}$

The covalent immobilization of Chitosan on dentinal collagen has been shown to induce remineralization of the demineralized dentin structure because its functional phosphate groups might bind to calcium ions to form a favorable surface for crystal nucleation, resulting in the formation of a calcium phosphate layer. ${ }^{30}$ Chitosan treatment improves the resistance of the dentinal surface to degradation by collagenase. ${ }^{31}$ Furthermore, chitosan presents with chelating capacity and also antimicrobial effects against a broad range of gram-positive and gram-negative bacteria as well as fungi. ${ }^{10,11,32,33}$ The chelating behavior of chitosan demonstrated in the present study indicates that this solution acted on the inorganic portion of the smear layer, favoring its removal and can be used as an alternative to EDTA.

The chitosan solution used in the present study was prepared using $1 \%$ acetic acid. According to the previous study by Silva et al., ${ }^{25}$ the smear layer removal capacity of chitosan was attributed to its own properties, instead of those of the $1 \%$ acetic acid. Thus, it was deduced that the chelating behavior of chitosan favored its smear layer removal.

In our study, $0.2 \%$ of chitosan was used based on the results of another in vitro study conducted by Silva et al., which concluded that $0.2 \%$ chitosan removed the smear layer adequately and caused less erosion than EDTA. ${ }^{25,34}$

Scanning electron microscopic analysis was carried out to evaluate the smear layer removal scores since it is a commonly used technique and has proved to be a valuable method for the assessment of smear layer. ${ }^{35-37}$ In the present study, group I showed the presence of a heavy smear layer throughout the length of the canals since normal saline had no chelating ability. Group II had the highest ability of smear layer removal, hence a combination of ultrasonics with EDTA was found to be effective in the removal of smear layer. This was similar to a study conducted by Amin et al., ${ }^{12}$ the efficacy of group III in the removal of smear layer was greater than group I, but the efficacy was less as compared to group II. The results were not in accordance with the study conducted by Darrag et al., ${ }^{38}$ which showed $0.2 \%$ chitosan to be more effective than $17 \%$ EDTA and $10 \%$ citric acid. This can be due to the use of ultrasonic activation in the present study, which shows better results when used in combination with EDTA.

The use of chitosan after irrigation with $\mathrm{NaOCl}$ is recommended because of the ability of the chitosan on dentin to resist bacterial adherence and early biofilm formation. ${ }^{38}$

A combination of chitosan-EDTA (1:1) has also been tried as an irrigating agent in several studies, and this has been reported to perform a dual role-root canal disinfection and smear layer removal. ${ }^{39-41}$ The $\mathrm{NH}^{3+}$ moieties present in the chitosan were reported to react with COO- moieties of EDTA to form ionic EDTA$\mathrm{CHT}$ complex. This is shown to have antimicrobial activity against Gram-positive and Gram-negative bacteria. ${ }^{21,22}$ EDTA potentiates the antibacterial activity of chitosan and facilitates the entry of chitosan into a bacterial cell. This is known to restrain the growth of microorganisms by enzyme inhibition. ${ }^{41-43}$ Hence, from the current study, it can be inferred that ultrasonically activated EDTA has the highest ability of smear layer removal.

\section{Conclusion}

Within the limitations of the current study, all the tested groups were able to remove the smear layer from the prepared root canals to different degrees. Both EDTA and $0.2 \%$ chitosan performed better than normal saline. EDTA was found to be more effective than chitosan. Further studies using various concentrations of chitosan and by using a combination of EDTA and chitosan need to be carried out to confirm the results, improve root canal disinfection, and smear layer removal.

\section{References}

1. McComb D, Smith DC. A preliminary scanning electron microscopic study of root canals after endodontic procedures. J Endod 1975;1(7):238-242. DOI: 10.1016/S0099-2399(75)80226-3.

2. MoodnikRM, Dorn SO, etal. Efficacy of biomechanical instrumentation: a scanning electron microscopic study. J Endod 1976;2(9):261-266. DOI: 10.1016/S0099-2399(76)80086-6.

3. Mader $\mathrm{CL}$, Baumgartner JC, et al. Scanning electron microscopic investigation of the smeared layer on root canal walls. J Endod 1984;10(10):477-483. DOI: 10.1016/S0099-2399(84)80204-6.

4. Torabinejad $M$, Handysides $R$, et al. Clinical implications of the smear layer in endodontics: a review. Oral Surg Oral Med Oral Pathol Oral Radiol Endod 2002;94(6):658-666. DOI: 10.1067/moe.2002.128962.

5. Kokkas $A B$, Boutsioukis $A$, et al. The influence of the smear layer on dentinal tubule penetration depth by three different root canal sealers: an in vitro study. J Endod 2004;30(2):100-102. DOI: 10.1097/00004770-200402000-00009.

6. Cobankara FK, Adanr N, et al. Evaluation of the influence of smear layer on the apical and coronal sealing ability of two sealers. J Endod 2004;30(6):406-409. DOI: 10.1097/00004770-200406000-00007.

7. Shahravan A, Haghdoost AA, et al. Effect of smear layer on sealing ability of canal obturation: a systematic review and meta-analysis. J Endod 2007;33(2):96-105. DOI: 10.1016/j.joen.2006.10.007.

8. Baumgartner JC Mader CL. A scanning electron microscopic evaluation of four root canal irrigation regimens. J Endod 1987;13:147157. DOI: 10.1016/S0099-2399(87)80132-2.

9. Mohammadi Z, Shalavi S, et al. Ethylenediaminetetraacetic acid in endodontics. Eur J Dent 2013;7:135-142. DOI: 10.4103/13057456.119091.

10. Kishen A, Shi Z, et al. An investigation on the antibacterial and antibiofilm efficacy of cationic nanoparticulates for root canal disinfection. J Endod 2008;34:1515-1520. DOI: 10.1016/ j.joen.2008.08.035.

11. Silva PV, Guedes DF, et al. Chitosan: a new solution for removal of smear layer after root canal instrumentation. Int Endod J 2013;46:332338. DOI: 10.1111/j.1365-2591.2012.02119.x.

12. Amin K, Masoodi A, et al. Effect of diode laser and ultrasonics with and without ethylenediaminetetraacetic acid on smear layer removal from the root canals: A scanning electron microscope study. J Conserv Dent 2016;19:424-427. DOI: 10.4103/0972-0707.190005.

13. Baumgartner JC, Cuenin PR. Efficacy of several concentrations of sodium hypochloritefor root canal irrigation. J Endod 1992;18: 605-612. DOI: 10.1016/S0099-2399(06)81331-2. 
14. Cameron JA. The use of ultrasonics in the removal of smear layer: a scanning electronmicroscope study. J Endod 1983;9:289-292. DOI: 10.1016/S0099-2399(83)80119-8.

15. Cameron JA. The use of ultrasound for the removal of the smear layer. The effect of sodium hypochlorite concentration: SEM study. Aus Dent J 1988;33:193-200. DOI: 10.1111/j.1834-7819.1988.tb01313.x.

16. Lui JN, Kuah HG, et al. Effect of EDTA with and without surfactants or ultrasonics on removal of smear layer. J Endod 2007;33:472-475. DOI: 10.1016/j.joen.2006.12.007.

17. De-Deus G, Souza EM, et al. Smear layer dissolution by peracetic acid of low concentration. Inter Endod J 2011;44:485-490. DOI: 10.1111/j.1365-2591.2010.01847.x.

18. Gopikrishna V, Venkateshbabu N, et al. Evaluation of the effect of MTAD in comparison with EDTA when employed as the final rinse on the shear bond strength of three endodontic sealers to dentine. Aust Endod J 2011;37(1):12-17. DOI: 10.1111/j.1747-4477.2010.00261.x.

19. Gutmann JL, Saunders WP, et al. Ultrasonic root-end preparation. Part 1. SEM analysis. Int Endod J 1994;27:318-324. DOI: 10.1111/j.13652591.1994.tb00276.x.

20. Baumgartner JC, Brown CM, et al. A scanning electron microscopic evaluation of root canal debridement using saline, sodium hypochlorite, and citric acid. J Endod 1984;10(11):525-531. DOI: 10.1016/S0099-2399(84)80137-5.

21. Economides $\mathrm{N}$, Liolios $\mathrm{E}$, et al. Long-term evaluation of the influence of smear layer removal on the sealing ability of different sealers. J Endod 1999;25:123-125. DOI: 10.1016/S0099-2399(99)80010-7.

22. Saunders WP, Saunders EM. Influence of smear layer on the coronal leakage of thermafil and laterally condensed gutta-percha root fillings with a glass ionomer sealer. J Endod 1994;20:155-158. DOI: 10.1016/S0099-2399(06)80325-0.

23. Ahmad M, Pitt Ford TR, et al. Ultrasonic debridement of root canals: an insight into the mechanisms involved. J Endod 1987;13:93-101. DOI: 10.1016/S0099-2399(87)80173-5.

24. Walmsley AD, Williams AR. Effects of constraint on the oscillatory pattern of endosonic files. J Endod 1989;15:189-194. DOI: 10.1016/ S0099-2399(89)80233-X.

25. Silva PV, Guedes DF, et al. Time dependent effects of chitosan on dentin structures. Braz Dent J 2012;23:357-361. DOI: 10.1590/S010364402012000400008.

26. Von der Fehr FR, Nygaard-Ostby B. Effect of EDTAC and sulfuric acid on root canal dentine. Oral Surg Oral Med Oral Pathol 1963;16:199-205. DOI: 10.1016/0030-4220(63)90033-1.

27. Pimenta JA, Zaparolli D, et al. Chitosan: effect of a new chelating agent on the microhardness of root dentin. Braz Dent J 2012;23(3):212-217. DOI: 10.1590/S0103-64402012000300005.

28. Shenoy A, AhmaduddinBolla N, et al. Effect of final irrigating solution on smear layer removal and penetrability of the root canal sealer. J Conserv Dent 2014;17:40-44. DOI: 10.4103/0972-0707.124132.

29. Zhang J, Xia Z, et al. Chitosan modification and pharmaceutical/ biomedical applications. Mar Drugs 2010;8:1962-1987. DOI: 10.3390/ md8071962.
30. Xu Z, Neoh KG, et al. Biomimetic deposition of calcium phosphate minerals on the surface of partially demineralized dentin modified with phosphorylated chitosan. J Biomed Mater Res B Appl Biomater 2011;98:150-159. DOI: 10.1002/jbm.b.31844.

31. Shrestha A, Friedman $S$, et al. Photodynamically crosslinked and chitosan-incorporated dentin collagen. J Dent Res 2011;90:1346-1351. DOI: $10.1177 / 0022034511421928$.

32. No HK, Park NY, et al. Antibacterial activity of chitosans and chitosan oligomers with different molecular weights. Int J Food Microbiol 2002;74:65-72. DOI: 10.1016/S0168-1605(01)00717-6.

33. Calamari SE, Bojanich MA, et al. Antifungal and post-antifungal effects of chlorhexidine, fluconazole, chitosan and its combinations on Candida albicans. Med Oral Patol Oral Cir Bucal 2011;16:e23-e28. DOI: 10.4317/medoral.16.e23.

34. Kamble AB, Abraham $S$, et al. Scanning electron microscopic evaluation of efficacy of $17 \%$ ethylenediaminetetraacetic acid and chitosan for smear layer removal with ultrasonics: An In vitro study. Contemp Clin Dent 2017;8:621-626.

35. Shashidhar C, Mehta DL. Scanning Electron Microscopic Evaluation of Efficacy of $17 \%$ Ethylenediaminetetraacetic Acid and Chitosan for Smear Layer Removal with Ultrasonics: An In vitro Study. Contemp Clin Dent 2017;8(4):621-626. DOI: 10.4103/ccd.ccd_745_17.

36. Mancini M, Cerroni L, et al. Smear layer removal and canal cleanliness using different irrigation systems (EndoActivator, EndoVac, and passive ultrasonic irrigation): Field emission scanning electron microscopic evaluation in an in vitro study. J Endod 2013;39: 1456-1460. DOI: 10.1016/j.joen.2013.07.028.

37. Yang $\mathrm{G}, \mathrm{Wu} \mathrm{H}$, et al. Scanning electron microscopic evaluation of debris and smear layer remaining following use of ProTaper and Hero Shaper instruments in combination with $\mathrm{NaOCl}$ and EDTA irrigation. Oral Surg Oral Med Oral Pathol Oral Radiol Endod 2008;106:e63-e71. DOI: 10.1016/j.tripleo.2008.04.032.

38. Darrag AM. Effectiveness of different final irrigation solutions on smear layer removal in intraradicular dentin. Tanta Den J 2014;11: 93-99. DOI: 10.1016/j.tdj.2014.06.002.

39. Gulabivala $\mathrm{K}, \mathrm{Ng} \mathrm{Y}-\mathrm{L}$, et al. The fluid mechanics of root canal irrigation. Physiol Meas 2010;31:R49-R84. DOI: 10.1088/0967-3334/31/12/R01.

40. Geethapriya N, Subbya A, et al. Effect Of Chitosan-Ethylenediamine Tetraacetic Acid On Enterococcus Faecalis Dentinal Biofilm And Smear Layer Removal. J Conserv Dent 2016;19:472-477. DOI: 10.4103/09720707.190022.

41. Raafat D, von Bargen K, et al. Insights into the mode of action of chitosan as an antibacterial compound. Appl Environ Microbiol 2008;74:3764-3773. DOI: 10.1128/AEM.00453-08.

42. Banin E, Brady KM, et al. Chelator-induced dispersal and killing of Pseudomonas aeruginosa cells in a biofilm. Appl Environ Microbiol 2006;72:2064-2069. DOI: 10.1128/AEM.72.3.2064-2069.2006.

43. Bernkop-Schnürch A, Scerbe-Saiko A. Synthesis and In Vitro Evaluation of Chitosan-EDTA-Protease-Inhibitor Conjugates Which Might Be Useful in Oral Delivery of Peptides and Proteins. Pharmaceutical Research 1998;15:263-269. DOI: 10.1023/A:1011970703087. 